\title{
Orphanhood and Living Arrangements of Children in Nepal
}

\author{
Arjun Mani Guragain ${ }^{1,2}$, Binita Kumari Paudel ${ }^{1}$, Apiradee $\operatorname{Lim}^{1} \&$ Chamnein Choonpradub ${ }^{1}$ \\ ${ }^{1}$ Department of Mathematics and Computer Science, Faculty of Science and Technology, Prince of Songkla \\ University, Pattani Campus, Pattani, Thailand \\ ${ }^{2}$ Child Haven International Canada/Nepal, Jorpati-7, Kathmandu, Nepal \\ Correspondence: Apiradee Lim, Department of Mathematics and Computer Science, Faculty of Science and \\ Technology, Prince of Songkla University, Muang, Pattani, 94000, Thailand. Tel: 66-081-957-7625, E-mail: \\ lapirade@bunga.pn.psu.ac.th; api_45@hotmail.com
}

\author{
Received: November 5, 2014 Accepted: January 20, 2015 Online Published: April 30, 2015 \\ doi:10.5539/ass.v11n12p84 \\ URL: http://dx.doi.org/10.5539/ass.v11n12p84
}

\begin{abstract}
Children's living arrangement plays a crucial role on their physical, emotional as well as social development. This study aimed to examine the living arrangement of children (both orphan \& non-orphan) based on a nationally representative Nepal Demographic and Health Survey (NDHS) 2006 and 2011. This study used total sample of 0-17 years children consist of 19935 and 20808 respectively in 2006 and 2011 survey. The survey package in statistical software $\mathrm{R}$ was used to analyze the data. Chi-square test and logistic regression model were employed as statistical tools. Of the total children, 5\% (95\% CI, 4.7-6.0) in 2006 and 5.3\% (95\% CI, 4.5-5.5) in 2011 were orphans. The number of paternal orphans almost doubled the number of maternal orphans in both surveys. Furthermore, approximately $7 \%(95 \%$ CI, 6.2-8.1) of the children lived apart from their biological parents in both surveys. This study also found that about one quarter of the children, representing $23.5 \%$ (95\% CI, 21.4-25.7) in 2006 and $28.7 \%$ (95\% CI, 26.8-30.6) in 2011 were living only with their biological mother. The multivariate analysis found that orphans were more likely to reside in poorest households, in households having no or unrelated adult, in female headed and more than50 year age group headed households. In conclusion, the proportion of children living with both parents had slightly decreased, whereas those living with mother had slightly increased over the time. The living arrangement in relation to household level characteristics between orphans and non-orphans was significantly varied.
\end{abstract}

Keywords: biological parent, DHS, living arrangement, Nepal, orphanhood, survey

\section{Introduction}

Family living arrangements greatly affects one's personal life. Living arrangements can be characterized by parental residence, marital status and the presence or absence of extended family members, including grandparents, other relatives, or non-relatives in the household (Landale, Thomas, \& Van Hook, 2011). Children's living arrangements have a greater role in their physical, social and emotional health and development, as they fully depend on their families. An ideal living arrangement for a child consists of living with both biological parents. A recent survey conducted by Lippman, Wilcox, \& Ryberg (2013) in 45 countries around the globe concluded that more than $80 \%$ of adults believe that the ideal living arrangements for a child is to have a mother and a father at home. Numerous studies have suggested that parents play an important role in the healthy growth and development of children. Children who grow and reside with the biological parents have demonstrated self-control behavior like; non- aggressive, self-confident, positive attitude and have less emotional or behavioural problems in comparison to those who live with their non-biological parents (Paul, 2005; Rosenberg, \& Wilcox, 2006; UNICEF Office of Research, 2013). Furthermore, the study conducted by Lippman et al. (2013) also underscored that the children living with the parents are more likely to achieve better results academically, including good literacy skills as these parents help the children and encourage study habits which contribute to their success in their studies and future careers. Not only do two-parent families fare better economically than single-parent families, but also children living with both biological parents are less likely to experience a range of cognitive, emotional, and social problems that have long-term consequences for their well-being (Paul, 2005). Thus, the living arrangement is key to children's overall growth and development.

If the parents separated or divorced, or if one or both parents deceased, as a result, the child's living arrangement will substantially change. It is all determined by the local culture, decision of immediate parent, 
recommendations from relatives and well-wishers like: close neighbors, distance relatives. These decisions have been based on traditions, beliefs, plan and practice on raising the children after one or both parents die. If the law is legitimate and implement well then the law also determined for the new living arrangements of the children (Kelly, 2006). It is an extremely essential to learn living arrangements of children to address their necessitates, troubles and fulfill their urgent needs, especially the children who are needy and under the care of the child headed households as they likely have limited sources and less excess on economic resources (Hill, Hosegood, \& Newell, 2008; Kipp, Arif Alibhai, \& Rubaale, 2010). It is also an important that parents and their children utilize social and economic resources together.

There have been numerous studies of living arrangements of children in developed countries. Several studies were conducted in the African countries where HIV/AIDS became an epidemic and millions of young adults, parents have deceased, to assess the children living arrangements and take necessary actions to assist and prevent the children from and to be measurable situation. In the context of Nepal, family structure has been changing from the extended family to nuclear family, urban population is increasing, (Ghimire \& Axinn, 2006) and thousands of children became orphaned as a result of a decade long political turmoil (Joshi, 2008; Sing, Dahal, \& Mills, 2005). However, the researchers, in their best search, could not find any scientific studies that conducted focusing on the living arrangement of children in Nepal except DHS survey and population census (NDHS, 2006; NDHS, 2011; Central Bureau of Statistics, 2012). Although the primary purpose of demographic and health survey was not the orphanhood and living arrangement, some questions were included related to this issue in 2006 and 2011 and presented only descriptive findings in the final report. There is only little known in this area from these reports. Hence, this study further analyzed DHS data by using advanced statistical method to expand this information.

This analysis aims to examine the different aspects of children's living arrangements in Nepal. Different aspects include living with biological parents, single biological parent and neither parent by their orphan status. In case of children living with neither parent, the relationship to the head of household was examined. The variation in living arrangement between orphans and non-orphans were investigated by using household level characteristics. The main body of the discussion focuses on different aspects of living arrangement and child welfare.

\section{Methods}

\subsection{Data, Sample Size and Sampling Method}

This study analyzed data from the Demographic and Health Survey (DHS) conducted in 2006 and 2011. Both surveys used two stage stratified cluster sampling method to select nationally representative samples of the households. The surveys collected the personal detail of all the members, including parent's survival status and living arrangements of all the children 0-17 years residing in the households. Thus, our sample was drawn as a subset of 0-17 year's children from individual records of all the household members. Since, the institutional household like orphanages or child care homes were not included in the survey, our sample is representative for all the children throughout the country reside only in the households. The total sample of 0-17 years children consist of 19935 and 20808 respectively in 2006 and 2011 survey.

\subsection{Defining Variables under Study}

In this study, a child is defined as a person aged 0-17 years. There were few children whose parent's survival status was reported to be "missing" only in 2006 survey and "do not know" in both 2006 and 2011 surveys. The children whose parent's survival status was reported as "do not know" were included in the analysis, but excluded those whose information was "missing". Orphan status of the children is categorized into four groups based on their parents' survival status as follows: non-orphan (both parents alive), maternal orphan (mother, deceased, but father alive), paternal orphan (father deceased but mother alive) and double orphan (both mother and father deceased). Furthermore, an orphan is defined as a child who's either one or both parents living status reported to be deceased for the purpose of modeling the data.

Living arrangement of the children is categorized into four groups based on their biological parents' residence together with their child or not as follows: living with both parents, living with mother only, living with father only and living with no parents.

\subsection{Statistical Methods}

Statistical analyses were carried out by using the survey package version 3.28-2 (Lumley, 2012; Lumley, 2004) in the statistical software system R version 3.0.2 (R Core Team, 2013) to account for the complex sampling design and weights to obtain appropriate standard errors for all estimates. 
The proportion estimation including $95 \%$ confidence interval of the children by their orphan status and living arrangement were calculated and presented in table for both 2006 and 2011. The children who lived without parents were further analyzed to see in detail with whom they were living, including relationship with their head of household.

In order to explore the association between orphan status and household level characteristics, Chi-square test was done. Finally, the variation in living arrangement of orphans and non-orphans by household level characteristics was assessed by logistic regression model. The coefficients and standard errors from the logistic regression model were used to calculate adjusted proportion with $95 \%$ CI and compared it with crude proportion in the figure. The present study used sum contrasts which give a measure of its difference for each level of each determinant factor from the overall mean of the outcome while fitting the logistic regression model. The household characteristics included relation to household head, age and sex of households head, relationship structure and the wealth index of the families.

\section{Results}

\subsection{Prevalence of Orphan and Living Arrangements}

Table 1. Frequency and percent distribution of children by orphan status and living arrangement in Nepal, 2006 and 2011

\begin{tabular}{lrrrr}
\hline & \multicolumn{2}{c}{$2006(\mathrm{n}=19772)$} & \multicolumn{2}{c}{$2011(\mathrm{n}=20839)$} \\
\cline { 2 - 5 } Description & Frequency & $\%(95 \% \mathrm{CI})$ & Frequency & $\%(95 \% \mathrm{CI})$ \\
\hline Orphan status & & & & \\
$\quad$ Non- orphan & 18719 & $94.6(94.0-95.3)$ & 19797 & $95.0(94.5-95.5)$ \\
Paternal orphan & 635 & $3.2(2.7-3.7)$ & 667 & $3.2(2.8-3.6)$ \\
$\quad$ Maternal orphan & 363 & $1.8(1.5-2.1)$ & 319 & $1.5(1.2-1.8)$ \\
Double orphan & 55 & $0.3(0.2-0.4)$ & 56 & $0.3(0.2-0.4)$ \\
Living-with & & & & \\
Neither parent & 1406 & $7.1(6.2-8.0)$ & 1520 & $7.3(6.5-8.1)$ \\
Mother only & 4654 & $23.5(21.4-25.7)$ & 5984 & $28.7(26.8-30.6)$ \\
Father only & 417 & $2.1(1.7-2.5)$ & 493 & $2.4(1.9-2.8)$ \\
Both parents & 13296 & $67.2(64.5-69.9)$ & 12841 & $61.6(59.6-63.7)$ \\
\hline
\end{tabular}

All the calculations were based on a weighted sample both in 2006 and 2011.

Abbreviation: CI- Confidence Interval

Table 1 shows the weighted frequency and percent distribution of the children with $95 \%$ confidence interval by their orphan status and living arrangement in 2006 and 2011. Of total children, 5\% (95\% CI, 4.7-6.0) in 2006 and $5.3 \%(95 \% \mathrm{CI}, 4.5-5.5)$ in 2011 were orphans. The numbers of paternal orphans were found almost double than the number of maternal orphans in both surveys. About 3 in 1000 children were found to be double orphan, meaning having no father or mother. Out of the total number of children, about $7 \%$ were livings with neither parent. As expected, children staying with their mother only were very high (about 25\%) compared to those staying with their father only (about $2 \%$ ). The cross tabulation between orphan status and living arrangement (Table 2) shows that out of total non- orphans only $71 \%$ in 2006 and $65 \%$ in 2011 living with both parents. About one quarter of non-orphans resided only with mother and about six percent lived with neither parent. One third (30\% in 2006 and $35 \%$ in 2011) of non-orphans reside separately from both of their parents.

The comparisons of last two surveys show no evidence of change in the prevalence of different types of orphans, but it shows some changes in living arrangements. The trend of living with both parents has been decreased by $6 \%$ over the period (Table 1 and 2), but the trend of living only with mother has been increased by same segment even- though the children have surviving father (non-orphan). The living arrangement among paternal orphan has not changed, but living with father only has been decreased by about $5 \%$ among maternal orphan.

It was found that about $7 \%$ of the children staying with neither parent (Table 1) in both surveys. The entire double orphans, one third of maternal orphans, over $16 \%$ of paternal orphans and more than $6 \%$ of non-orphans resided apart from their parents (Table 2). Table 3 shows the detail information about these children and their relationship to the head of the households. Out of total children staying with neither parent, about one third (33\% in 2006 and $34 \%$ in 2011) were staying with grandparents followed by other relatives $28.7 \%$ in 2006 and $32 \%$ in 2011. It is also noted that a substantial percentage of children were living in-law headed households (12\%), 
sibling headed household (9\%) and living as not-related family member (8\%) in both surveys. Only few children (about $2 \%$ ) were living as foster or adopted children.

Table 2. Percentage distribution of the children by their orphan status and living arrangement in Nepal, 2006 and 2011

\begin{tabular}{|c|c|c|c|c|c|c|}
\hline \multirow[b]{2}{*}{ Orphan Status } & \multirow[b]{2}{*}{ Year } & \multicolumn{4}{|c|}{$\%$ of children living with ${ }^{\mathrm{a}}$} & \multirow[b]{2}{*}{ Total children } \\
\hline & & No parents & Mother only & Father only & Both parents & \\
\hline \multirow[t]{2}{*}{ Non-orphan } & 2006 & 6.04 & 22.04 & 0.89 & 71.03 & 18719 \\
\hline & 2011 & 6.27 & 27.41 & 1.46 & 64.87 & 19797 \\
\hline \multirow[t]{2}{*}{ Paternal orphan } & 2006 & 16.85 & 83.15 & - & - & 635 \\
\hline & 2011 & 16.47 & 83.53 & - & - & 667 \\
\hline \multirow[t]{2}{*}{ Maternal orphan } & 2006 & 30.98 & - & 69.02 & - & 363 \\
\hline & 2011 & 35.65 & - & 64.35 & - & 319 \\
\hline \multirow[t]{2}{*}{ Double orphan } & 2006 & 100 & - & - & - & 55 \\
\hline & 2011 & 100 & - & - & - & 56 \\
\hline
\end{tabular}

${ }^{a}$ Row percentage

Table 3. Percent distribution of children staying apart from biological parents and their relationship to household head

\begin{tabular}{lcccc}
\hline \multirow{2}{*}{ Relationship to Household Head } & \multicolumn{2}{c}{$2006(\mathrm{n}=1406)$} & \multicolumn{2}{c}{$2011(\mathrm{n}=1520)$} \\
\cline { 2 - 5 } & Frequency & $\%$ & Frequency & $\%$ \\
\hline Head & 49 & 3.5 & 47 & 3.1 \\
Wife or husband & 46 & 3.3 & 18 & 1.2 \\
Son- in- law/daughter-in-law & 173 & 12.3 & 176 & 11.6 \\
Grandchild & 461 & 32.8 & 515 & 33.9 \\
Brother/sister & 128 & 9.1 & 139 & 9.1 \\
Other relative & 404 & 28.7 & 487 & 32.0 \\
Adopted/foster child & 35 & 2.5 & 35 & 2.3 \\
Not related & 109 & 7.8 & 104 & 6.8 \\
\hline
\end{tabular}

\subsection{Variation in Living Arrangement between Orphan and Non-Orphan}

Whether there are any differences in living arrangements between orphan and non-orphan were assessed by investigating the association between orphan status and household level characteristics. Household level characteristics included the relation to head of households, relationship structure, age and sex of the head of the households and wealth index. Univariate analysis illustrated that all the household level factors were significantly associated with orphaned except the age of the head of the households in 2006 (Table 4). All these factors were included in the multivariate analysis. Figure 1 shows the crude and adjusted percentage of orphans in different household level characteristics. Red horizontal lines represent the overall proportion of orphan children (5.3\%) in 2006 and (5.0\%) in 2011 and the bars represents the crude percentage.

Orphans were more likely to live in poor economic status households and less likely to live in rich economic household status. However, there was no strong statistical evidence $(\mathrm{P}$ value $\leq 0.05)$ to claim this variation since confidence interval for each level were not varied with average proportion of orphan in both surveys. The proportions of an orphan living with no or unrelated adult (more than 13\%) were found significantly higher than the overall proportion both in $2006(5.3 \%)$ and 2011 (5\%). The figure also reveals that the proportions of orphan were less likely to live in normal families which had two adult opposite sex. The study specified that significantly higher proportion of orphans resided in female headed households compared to average orphan living households. More than $12 \%$ of orphans reside in the female headed households comparing to male headed households where only $3 \%$ of orphans resided in 2006 and the proportion was steady in 2011 . The proportion of orphans, staying in a different age-group headed household was not significantly different in 2006 but it was indistinct different in 2011. The proportion of orphan were significantly lower in the younger age $(<40)$ headed household in 2011 but the proportion of orphans were significantly higher in the older than 50 years headed households. 
Table 4. Result from univariate analysis between orphanhood and household level characteristics

\begin{tabular}{|c|c|c|c|c|c|c|c|c|}
\hline \multirow[b]{2}{*}{ Household level Characteristics } & \multicolumn{4}{|c|}{2006} & \multicolumn{4}{|c|}{2011} \\
\hline & $\begin{array}{c}\text { Non-orphan } \\
(\mathrm{n}=18720)\end{array}$ & $\begin{array}{c}\text { Orphan } \\
(1053)\end{array}$ & $F(d f 1, d f 2)$ & $\mathrm{P}$ values & $\begin{array}{c}\text { Non-orphan } \\
(\mathrm{n}=19 \mathrm{798})\end{array}$ & $\begin{array}{c}\text { Orphan } \\
(1042)\end{array}$ & $F(\mathrm{df} 1, \mathrm{df} 2)$ & P values \\
\hline Relation to head of household & & & $29.7(4,510)$ & $<0.001$ & & & $402.1(4)$ & $<0.001$ \\
\hline Head/Spouse & 90 & 14 & & & 62 & 5 & & \\
\hline Son/Daughter & 13522 & 632 & & & 14520 & 629 & & \\
\hline Close relatives & 4168 & 228 & & & 4323 & 225 & & \\
\hline Other relatives & 844 & 155 & & & 821 & 149 & & \\
\hline Unrelated & 96 & 24 & & & 72 & 34 & & \\
\hline Relationship Structure & & & $21.0(4,494)$ & $<0.001$ & & & $15.1(4,986)$ & $<0.001$ \\
\hline No/unrelated adults & 285 & 43 & & & 248 & 30 & & \\
\hline One adult & 1773 & 209 & & & 2415 & 208 & & \\
\hline Two adults - opposite sex & 5262 & 170 & & & 5161 & 150 & & \\
\hline Two adults - same sex & 732 & 97 & & & 965 & 99 & & \\
\hline Three related adults & 10667 & 533 & & & 11007 & 554 & & \\
\hline Age of head of household & & & $2.0(4,542)$ & 0.127 & & & $6.1(4,1015)$ & $<0.001$ \\
\hline$<30$ years & 2731 & 169 & & & 2842 & 122 & & \\
\hline $31-40$ years & 5807 & 266 & & & 6259 & 231 & & \\
\hline $41-50$ years & 4619 & 312 & & & 4534 & 260 & & \\
\hline $51-60$ years & 3003 & 166 & & & 3252 & 245 & & \\
\hline$>60$ years & 2559 & 141 & & & 2910 & 185 & & \\
\hline Sex of head of household & & & $139.5(1,143)$ & $<0.001$ & & & 177. $8(1,264)$ & $<0.001$ \\
\hline Male & 15169 & 557 & & & 14619 & 451 & & \\
\hline Female & 3550 & 497 & & & 5178 & 591 & & \\
\hline Wealth Index & & & $2.5(4,528)$ & 0.049 & & & $3.1(4,994)$ & 0.019 \\
\hline Poorest & 4242 & 303 & & & 4722 & 312 & & \\
\hline Poorer & 3933 & 231 & & & 4190 & 240 & & \\
\hline Middle & 3814 & 171 & & & 3942 & 207 & & \\
\hline Richer & 3520 & 202 & & & 3673 & 146 & & \\
\hline Richest & 3210 & 147 & & & 3271 & 137 & & \\
\hline
\end{tabular}
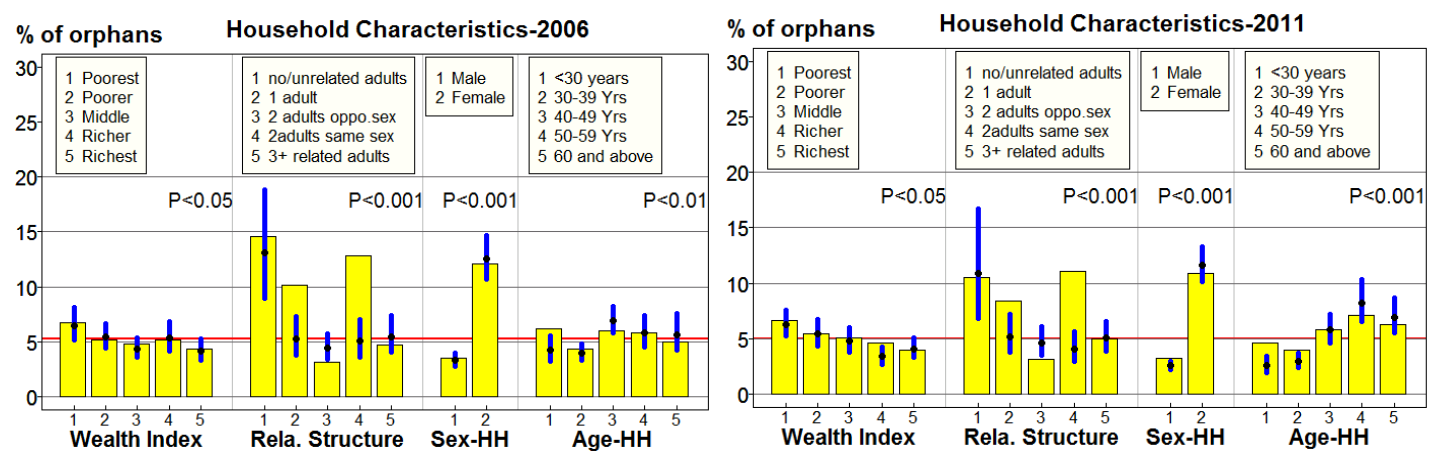

Figure 1. Observed and adjusted percent of orphan children with $95 \%$ confidence interval by household level characteristics, 2006 and 2011

\section{Discussion}

It is frequently believed that children live with their biological parents, experience their childhood together with other siblings and utilize the available resources of their parents. But in fact substantial numbers of children, in the world, are deprived of such an ideal living condition due to many reasons. This study found that more than one quarter of the children in Nepal were experiencing their childhood only with single parent and $6-8 \%$ of children were living with neither parent. This study focused on living arrangements and welfare of these children's and discussed the possible reasons. 


\subsection{Living with Single Biological Parent}

While about one quarter of all the children were found living with mother only, but very small percentages of children were found living only with father in both surveys. Paternal orphan were found double than maternal orphan. It was also found that almost all the paternal orphans were found staying with mother. This could be one of the reasons behind the high proportion of children living with mother comparing to father. Another reason of these huge proportions of children staying only with mother could be temporary migration of their father into a foreign country for the employment. According to the department of foreign employment of Nepal, more than 1.8 million males migrated abroad between 2008-2014 excluding India for the same purposes.

An International study conducted in many countries highlighted that children living with both parents, more likely to follow their parent's guideline, do well in school and keen on reading than are children living with one or no parents. This report also claims that the extra resource that two parents provide to the children is huge advantages. However, same reports presented contradict findings in the least developing countries. Single parent household's children often do well as or even do better than two-parent household's children do. The reasons could be these families more likely to receive social and financial support from distance relatives or migrant worker who is working far away, do transfer the resources to the family where children reside. It also could be possible that children get benefit from single mothers when mothers invest more for their children's schooling than fathers do and have more influence in resources and decision-making that enhance children's education (Lippman et al., 2013).

\subsection{Living Apart from the Biological Parent and a Relationship with the Household's Head}

While the vast majority of children reside with one or both parents, single or double orphan are less likely to reside with a parent than non-orphan. This study found that only $7 \%$ of both orphans and non-orphans were living with neither parent. However, this is higher than neighboring countries, China and India $(2-5 \%)$ and Europe (2-5\%), North America (2-5\%), but a lower compared to $10-20 \%$ in Sub-Saran Africa (Lippman et al.,2013). It is an important to disclose with whom they are staying. Hence, we further assessed the relationship of these children to their household head.

Despite of the child's interest of living with both parents, most of the children outside parental care live with their extended family under a kinship care arrangement in South Asia (UNICEF, regional office for South Asia, 2008).This study also found that out of total children staying with neither parent, about one third were staying with grandparents and another one third was staying with other relatives. A separate study in different country disclosed that $52.7 \%$ in Thailand followed by $38 \%$ in Cambodia and $17 \%$ in Vietnam the double orphans were living with the grandparents headed households. Grand children get benefit from the grandparents' experience that they share in their fresh mode. And $45 \%$ in Cambodia, followed by $30 \%$ in Thailand and $12 \%$ in Vietnam orphans reside with other distance relatives. (Cambodia Demographic and Health Survey (DHS) (2005); Thailand Multiple Indicator Cluster Survey (MICS) (2006); Vietnam Population and AIDS Indicator Survey (VPAIS) (2005).

In Nepal, child marriage is also prevalent (World Health Report, 2006) and the girls have to move to the husband's family. It is also noted in this study that substantial percentage of children were already married and some of them $(12 \%)$ were living in-law headed households, as well, some others became the spouse of the head of the child headed households (3\%). About $6 \%$ of the non-orphans were living apart from biological parents in Nepal, could be for the better academic performance and achievement as reported from the study conducted in three ASEAN countries like Thailand (8\%), Cambodia $(6 \%)$ and Vietnam $(3 \%)$ children staying apart from biological parents for the same purpose (UNICEF EAPRO 2009; The National Multi-Sectoral Orphans and Vulnerable Children Task Force 2008) also present that both orphans and non-orphans who stay with other relatives in Cambodia, more likely to have a higher pattern of school attendance.

Adoption is not so common in Nepal. If someone adopted a child legally, s/he would claim him/her as their own child. Only few children (about 2\%) were found living as foster or adopted children, but $8 \%$ children in both surveys were found living with not-related family member. A study in Sub-Saharan Africa revealed that children rearing among the family members and with others are a general practiced phenomenon of the society of sharing broader child support system. Child fostering is not only due to lack of, inadequate resources, but for providing the opportunity and strengthen the family relationship (Lloyd \& Desai, 1992; Kathleen, Filmer, Stokes, \& Tiererova, 2009). 


\subsection{Variation in Living Arrangements between Orphan and Non-Orphan}

As stated in the introduction section of this paper, when one or both parents deceased, living arrangements would change as per decision of immediate parents or relatives based on local culture or legislation. Therefore, it is expected that there would be variation in the living arrangement between orphans and non-orphans. The result from our multivariate analysis also found the evidence of a significant association between orphan status and different household level characteristics like wealth index, relationship structure, sex and age of household head.

\subsubsection{Economic Context of the Family and Orphan}

This study found that the proportion of orphans were relatively high in the poorest households and relatively low in the richer and richest households. However, there was no strong statistical evidence to claim this variation since confidence interval for each level were not varied with average proportion of orphan in both surveys. This study is also unable to assess the temporal association and could not explain whether the families were poor before children become an orphan or it happens after parent's death. A study conducted on Cambodia, Thailand and Vietnam concluded that prevalence of orphans is much higher among the poorest households (UNICEF EAPRO, 2009).

\subsubsection{Relationship Structure of the Family and the Orphan}

The common structure of a nuclear family includes two adults of the opposite sex where the extended family may have three or more related adults. The family without any adult members or family with unrelated adults cannot be considered as a usual family structure. This study found that orphans were more likely to live in the family with no or unrelated adults. The orphans who are staying themselves without any adult members may have faced a range of challenges, including huge economic crises and inadequate services access. Similarly, the orphan who is staying with unrelated adults might have abused by adults. A study conducted in Sub-Sahara Africa found that one in 10 households were child headed households where there was limited access of basic needs including education and more likely to have abused. However, abuse cases generally do not report as of fear of revenge (Earnshaw, Niongwe, English, \& Worku, 2009). A study in South Africa revealed the contradictory result that significantly low $(0.47 \%)$ children reside in child headed households and its remain steady. Surprisingly, more than $92 \%$ of those children headed households have living parents (Meintjes, Hall, Marera, \& Boulle, 2010).

\subsubsection{Sex and Age of Household Head and Orphan}

This study provides evidence that a significantly higher proportion of orphans were living in the female headed households and a significantly lower proportion of orphans were living in male headed households, both in 2006 and 2011 comparing the overall proportion of orphans. Numerous studies, in the past also indicated that the significantly higher proportion of orphans reside in the female headed households (Bicego, Rutstein, \& Johnson, 2003; UNAIDS, UNICEF \& USAIDS, 2004; The National Multi-Sectoral Orphans and Vulnerable Children Task Force, 2008). The reason behind the higher proportion of orphan reside in the female headed households could be female is more likely to care the orphans than male-headed households, it is also common that the father could stay elsewhere more easily (UNAIDS, UNICEF and USAIDS, 2004). Age of household head where orphans reside is also a concern form the prospective of children's welfare. Although, it was found a bit different result in two surveys, it can be concluded that orphans are less likely to live in a household headed by less than 40 years of age whereas more likely to live in households headed by more than 50 years.

\section{Conclusion}

This study concluded that the proportion of children living with both parents had slightly decreased in 2011 compared to 2006 survey, but living with mother only and other relatives had slightly increased over the time. The household level characteristics in link of orphan and non-orphan living arrangements were significantly different. The higher proportions of orphans were found in the female headed household, with no adults or unrelated adults, economically challenged households.

This study was limited to the description of the living arrangements of children only. However, it is, nevertheless, an important element to consider when understanding the case of orphans in Nepal, as it can provide an invaluable reference for related authorities and other concerned organizations, which are working for the welfare of these children. A further study is essential to investigate orphaned children's overall well-being, in terms of their safety, their access to quality education and health, especially while considering the different living arrangements, such as those orphans residing with no adults or un-related adult, in a female-headed household, with their grandparents, with other relatives, or have become foster children of unrelated family. 


\section{Acknowledgements}

The authors would like to acknowledge DHS measure for providing the data. They also would like to thank Emeritus Professor Don McNeil and Edward McNeil for their tremendous guidance in analyzing data. Finally, Principal Investigator would like to appreciate the Faculty of Science and Technology of Prince of Songkla University, Pattani Campus for providing ASEAN scholarship and graduate school for proving thesis support grant.

\section{References}

Bicego, G., Rutstein, S., \& Johnson, K. (2003). Dimension of Emerging Orphan Crisis in Sub-Saharan Africa. Social Science \& Medicine, 56, 1235-1247.

Central Bureau of Statistics (CBS). (2012). National Population and Housing Census 2011 (National Report). Government of Nepal (GON), National Planning Commission Secretariat (NPCS), CBS, Kathmandu, Nepal.

Earnshaw, S., Njongwe, P. Z., English, B., \& Worku, Z. (2009). The health and living conditions of children in child-headed households in Siteki, Swaziland. East African Journal of Public Health, 6(1), 95-101

General Statistical Office (GSO), National Institute of Hygiene and Epidemiology (NIHE) [Vietnam] and ORC Macro. 2006. Vietnam Population and AIDS Indicator Survey 2005. Calverton, Maryland, USA: GSO, NIHE, and ORC Macro.

Ghimire, D. J., \& Axinn, W. G. (2006). Family change in Nepal: Evidence from Western Chitwan. Contributions to Nepalese Studies Journal, 33(2), 177-201

Hill, C., Hosegood, V., \& Newell, M. L. (2008). Children care and living arrangements in a High HIV prevalence area in rural South Africa. Vulnerable Children and Youth Studies, 3(1), 65-77. http://dx.doi.org/10.1080/ 17450120701602091

Joshi, A. (2008). Impact of Armed Conflict on Children in Nepal: Situational Analysis of their Health Status. Kathmandu School of Law, Child Rights Research and Resource Center, Nepal.

Kathleen, B., Filmer, D., Stokes, A., \& Tiererova, L. (2009). Orphanhood and the living arrangements of children in Sub-Saharan Africa. The World Bank. Washington, DC. http://dx.doi.org/10.1596/18139450-4889

Kelly, J. (2007). Children's Living Arrangements Following Separation and Divorce: Insights from Empirical and Clinical Research. Family Process, 46(1), 35-52.

Kipp, W. E., Arif Alibhai, F. S., \& Rubaale, T. (2010). Needs and support for Ugandan Child-headed households: results from a qualitative study. Vulnerable Children and Youth Studies, 5(4). http://dx.doi.org/10.1080/ 17450128.2010 .507805

Landale, N. S., Thomas, K. J. A., \& Van Hook, J. (2011). The Living Arrangements of Children of Immigrants. Future Child, 21(1), 43-70.

Lippman, L., H., Wilcox, W., B., \& Ryberg, R. (2013). World Family Map 2013: Mapping Family Change and Child Well-Being Outcomes. Child Trends, Bethesda. http://www.childtrends.org/?publications=worldfamily-map-2013-mapping-family-change-and-child-well-being-outcomes\#sthash.T1qO3d7S.dpuf

Lloyd, C. B., \& Desai, S. (1992). Children living arrangements in developing countries. Population Research and Policy Review, 11(3), 193-216.

Lumley, T. (2004). Analysis of complex survey samples. Journal of Statistical Software, 9(1), 1-19.

Lumley, T. (2012). Survey analysis of complex survey samples (package version).

Meintjes, H., Hall, K., Marera, D. H., \& Boulle, A. (2010). Orphan of the AIDS epidemic? The extent, nature and circumstances of child-headed households in South Africa. AIDS Care, 22(1), 40-49. http://dx.doi.org/10.1080/09540120903033029

Ministry of Health and Population (MOHP) [Nepal], New ERA, and ICF International Inc. (2006). Nepal Demographic and Health Survey (NDHS) 2006. Kathmandu, Nepal: Ministry of Health and Population, New ERA, and ICF International, Calverton, Maryland.

Ministry of Health and Population (MOHP) [Nepal], New ERA, and ICF International Inc. (2012). Nepal Demographic and Health Survey (NDHS) 2011. Kathmandu, Nepal: Ministry of Health and Population, New ERA, and ICF International, Calverton, Maryland. 
Ministry of Labor and Employment, Department of foreign Employment. (2014). Labour Migration for Employment, A Status Report for Nepal: 2013/2014. Retrieved from http://www.migration4development. org/sites/m4d.emakina-eu.net/files/report_on_labour_migration_for_employment__nepal.pdf

National Institute of Public Health, National Institute of Statistics [Cambodia] and ORC Macro. (2006). Cambodia Demographic and Health Survey 2005. Phnom Penh, Cambodia and Calverton, Maryland, USA: National Institute of Public Health, National Institute of Statistics and ORC Macro.

Paul, R. A. (2005). The Impact of Family Formation Change on the Cognitive, Social, and Emotional well-being of the Next Generation. Marriage and Child Wellbeing, 15(2), 75-96.

R Core Team. (2013). R A language and environment for statistical computing Foundation for Statistical Computing, Vienna, Austria. Retrieved from http://www.R-project.org/

Rosenberg, J., \& Wilcox, W. B. (2006). The Importance of fathers in the healthy development of Children. The Office on Child Abuse and Neglect (OCAN), the Children's Bureau of the Administration for Children and Families (ACF), U.S. Department of Health and Human Services (DHHS)

Sing, S., Dahal, K., \& Mills, E. (2005). Nepal's War on Human Rights: A Summit Higher than Everest. International Journal for Equity in Health, 4(9). http://dx.doi.org/10.1186/1475-9276-4-9

Thailand National Statistical Office. (2006). Thailand Multiple Indicator Cluster Survey 2005-06, Final Report. Bangkok, Thailand: National Statistical Office.

The National Multi-Sectoral Orphans and Vulnerable Children Task Force (2008). Orphans Children Affected by HIV and Other Vulnerable Children in Cambodia. A Situation and Response Assessment 2007.National AIDS Authority.

UNAIDS, UNICEF \& USAIDS. (2004). Children on Brink 2004-A Joint Report of New Orphan Estimates and a Framework for Action. Health and Nutrition Information Project under USAID.

UNICEF EAPRO. (2009). Access to Essential Needs and Services for Children-Orphans and Poverty Status: A study on Cambodia, Thailand and Viet Nam. UNICEF East Asia and Pacific Regional Office, Bangkok, Thailand.

UNICEF Office of Research. (2013). Child Well-being in Rich Countries: A comparative overview, Innocenti Report Card 11, UNICEF Office of Research, Florence.

UNICEF, regional office for South Asia. (2008). What you can do about alternative care in South Asia. An advocacy kit. Kathmandu, Nepal.

World health report. (2006). Married Adolescents, No Place of Safety. World Health Organization, 20 Avenue Appia, 1211 Geneva 27, Switzerland.

\section{Copyrights}

Copyright for this article is retained by the author(s), with first publication rights granted to the journal.

This is an open-access article distributed under the terms and conditions of the Creative Commons Attribution license (http://creativecommons.org/licenses/by/3.0/). 